\title{
A Simplified Model to Predict Smoke Movement in Vertical Shafts During a High-Rise Structural Fire
}

\author{
Xutao Zhang ${ }^{1 *}$, Songling Wang $^{1}$, Jiangjiang Wang ${ }^{1}$ and Reina Giacomo ${ }^{2}$ \\ ${ }^{I}$ School of Energy and Power Engineering, North China Electric Power University,Baoding, Hebei Province, China \\ ${ }^{2}$ School of Civil Engineering and Geosciences, Newcastle University, Newcastle Upon Tyne, United Kingdom
}

Received 20 January 2014; Accepted 19 June 2014

\begin{abstract}
A simplified two-layered zonal model coupled with a network model is developed to predict the smoke movement in vertical shafts such as stairwells and elevator shafts during a high-rise fire. The main governing equations of smoke movement consist of conservation equations of mass and energy, convective heat transfer, radiative heat transfer and momentum transfer. It is essential to consider the temperature distribution in the vertical shaft, the buoyancy-induced flow and heat transfer results of strong upward forces known as "stack effect". This model is aiming at predicting the smoke movement in order to develop a successful fire protection plan and improve the occupants' safety in the event of fire. The model analysis yields three main measures to improve safety on the upper floors, including increasing the vent size on the top of the elevator shaft, pressurizing the floors except the fire floor and reducing the gaps around elevators. These measures can also raise the location of neutral pressure plane (NPP) which is critical for upper floor smoke controls. Ultimately, the location of NPP can be raised above the total height of structure, thus the smoke will be kept inside and exhausted out of the elevator shaft.
\end{abstract}

Keywords: Smoke movement, Stack effects, Elevator shafts, Neutral Pressure Plane, Pressurizing floors, High-rise fire

\section{Introduction}

In the last decade, the number of high-rise buildings has increased rapidly in China, and much more complicated synthetic materials have been applied for interior decorations. As a result, the smoke control system is more complicated during high-rise fires. Most fire deaths are not caused by burns, but by smoke inhalation. The fire-generated smoke can travel across long distances from the fire source and incapacitates upper floors so quickly through vertical shafts under the buoyancy forces. Thus, as a fire grows inside a building, the vertical shafts in high-structure like stairwells, elevator shafts and warehouses, can be critical routes of toxic smoke migration. Many research papers have been published on the impacts of fire smoke controls on safety, and different models for smoke movement, such as field models, zone models and network models [1-8] have been developed. A novel hybrid fire model integrated with the field and zone models was developed to simulate the smoke propagation in a multi-storey building, in which consists of a room on fire and two-layer zone model for the corridors [5]. The room on fire is divided into an arbitrary number of horizontal layers, in which the temperature and some other physical properties for each layer is assumed to be uniform with a good agreement between experimental and theoretical results [8].

The stack effect or namely "chimney effect" is often observed due to the temperature difference between the hot

\footnotetext{
*E-mail address: xyncepu@126.com
}

ISSN: 1791-2377 @ 2014 Kavala Institute of Technology. All rights reserved. smoke gas in the shaft and the low temperature air in the outside environment. This is the major driven force for the smoke movement in most high-rise structural fires. The smoke movement via vertical shafts becomes particularly important that the hot smoke encounters less resistance as moving upward. There is a concept of a horizontal elevation in the shaft called the neutral pressure plane (NPP), where the gas pressure inside the shaft is the same as the outside environment. Thus, a switch point of smoke flow direction as into or out of the shaft occurs which depends on location of smoke relative to the position of NPP. Below the NPP, the cold fresh air enters the shaft and mixes with the hot smoke. Above the NPP, the flow is reversed such that the hot smoke leaves the shaft and enters floors, which can threaten the occupant safety. Therefore, the solution is to increase the location of the NPP so that toxic smoke would not enter occupied areas and instead would exit via the vent installed on the top of the shaft. Many research papers have been published focusing on the smoke control in the vertical shafts [9-14]. For example, Miller and Beasley [9, 10] conducted analysis of stairwell and elevator shaft pressurization for smoke control in tall buildings using CONTAM software. As a result of Miller and Beasley's research, stairwell pressurization is more feasible in the absence of shaft pressurization, while coupled elevator shaft pressurization systems can produce significantly large pressure differentials across both the elevator and stairwell doors. The results lead to the fact that elevator pressurization is much more complex than stairwell pressurization, as stairwell doors are well sealed and closed during 
pressurization operation. Wang and Gao [11] found that the performance of stairwell-pressurization system was compromised in a 32-storey building during field tests where more than two stairwell doors were opened simultaneously. $\mathrm{Xu} \mathrm{X} . \mathrm{Y}$. etc. $[12,13]$ presented a simplified continuous model for neural pressure plane in shafts including each layer uniformly distributed along the vertical direction. However, the temperature profile inside the shaft is assumed to known from data obtained by Fire Dynamic Simulator (FDS). Mercier and Jaluria [14] did an experimental study on the flow and heat transfer in open vertical shafts, and found that a recirculation flow arises away from the wall which affects the heat transfer and flow inside the shafts.

As stated above, it is feasible for stairwell pressurization with the fire doors being well sealed, and the elevator shaft turns into the least-resistance path for smoke movement. It is important to take some measures to exhaust the smoke inside the shaft and prevent them from entering the upper floors. Similar to the stairwell pressurization, the floor pressurization can be taken into design by supplying more conditioned air from air handling units (AHUs) to pressurize the occupied areas. W.Z. Black [15-20] conducted further studies on the smoke control during high-rise fires using the COSMO codes, which is under development. The radiative heat transfer is addressed by a radiosity-irradiation analysis, in which the radiosities of six surfaces (four surfaces of the shaft and the upper and lower surfaces of the gas layer) are considered. The net radiative heat transfer from the elemental volume of smoke is calculated. The floor pressurization system can be triggered by a smoke alarm system or the sprinkler system, and the AHUs pressurize the floors above the fire floor, with the return air dampers being fully closed to introduce $100 \%$ fresh air. The floor pressure above the floor on fire is therefore increased. The smoke in the vertical shaft can not enter the upper floors since the location of NPP is increased. The results lead to the concept that the volume flow rate is adjustable and can be modulated at AHUs $[18,20]$.

The smoke models can deal with a lot of factors which influence the movements of combustion gases. The movement of smoke rising upward inside the shaft is greatly influenced by its properties, primarily the pressure, temperature and density. The smoke models can be classified as three main types: field models, zone models and network models [21]. Field models divide the object into a large amount of cells and the governing equations are solved for each cell. The gas properties such as the pressure, temperature, smoke concentration, etc., can be simulated in the results as well, but with increased computational time. Therefore, the field models are appropriate for the fire room, not for the whole structure [27, 28]. In addition, the gaps around doors or windows and the opening area of the building constructions are not well handled in the field models. Zone models assume that the object is divided into three layers: a hot heavy smoky upper layer, a cool smokefree lower layer and a plume of combustion gas, in which the gas properties are assumed uniform. The zonal models are typically limited to a few compartments adjacent to the fire room. Network models are more appropriate for simulating a large structure due to the assumptions of a uniform set of properties within each node, typically a single floor or a single compartment. However, the detailed gas parameter distribution profile cannot be obtained, which are necessary for analyzing the area close to the fire source. The smoke control systems in the high-rise building can be calculated using network models, for example the stairwell pressurization, the smoke exhausting system, the flow gas across the gaps around doors/windows. However, the downside of the network modes are missing heat transfer analysis, assumptions made for constant temperature inside the compartments, or missing temperature or pressure distribution profile. This can lead to an inaccurate estimate of the smoke movement. Due to the characteristics of these models, an integrated model, such as field-zone-network (FZN) model or zone-network model, is considered to analyze smoke movement, while the tightness of building construction and the gaps around doors are neglected.

This study utilizes the simplified two-layered zone and network model to characterize the pressure distributions and temperature profiles of smoke movement, due to stack effect in the vertical shafts. The energy conservation is considered in the network model. Heat transfer considered in the energy conservation equations as a combination of convective and radiative heat transfer [29]. The Radiation Energy Absorption Distribution (READ) method is used for the calculation of radiative heat transfer, in which the coefficient of READ is obtained through Monte-Carlo Method as discussed later in the context. In addition to the model presented in this paper, the vertical shaft model is divided into multiple horizontal layers, the same number as the one of floors, with uniform physical properties assigned to each layer. Calculations are conducted on the gaps around elevator door, the opening area of the construction materials, the volume flow rate supplied on each floor above the fire floor and the vent size on the top of shaft. There is good implications obtained from the analysis results, such as the location of NPP and the amount of smoke to exhaust, to develop safety smoke control and safety improvement plans.

\section{Smoke Control Model}

The smoke movement inside the vertical shaft during highrise fires is governed by basic laws of physics including conservation of mass, momentum and energy, together with fluid mechanics and heat transfer. The basic equations based on these laws are sufficient to solve the gas properties in the shaft, and provide detailed quantitative information about the gas properties with reasonable accuracy. However, the model has several limitations due to some factors difficult to be determined, for example the wind velocity and wind patterns. Thus, the smoke control plan must be supplemented by sound judgment and engineering experience.

\subsection{Model Assumptions}

The equations are developed based on ideal conditions, and there are always some constraints for the calculated results. The assumptions are necessary to simplify the mathematic models to predict the smoke movement in vertical shafts. The conservation equations can be solved under the following assumptions:

- The smoke movement in vertical shafts is steady-state and considered to be one-dimensional. In other words, the properties of the smoke vary only with the elevation of the shaft and do not vary with time.

- The stairwell doors are closed. There is no pressurization considered in the calculation. 
- The gas pressure and temperature in the vertical shaft are uniform for each layer. The gas temperature in each floor, except the fire floor, is set to be the environment temperature. Only the conservation of energy in the vertical shaft is just considered.

- The hot gas thermodynamic properties such as the thermal conductivity, viscosity and thermal expansion coefficient do not change along with the gas temperature.

- The combustion gases and the fresh air are ideal gases with identical thermodynamic, yet different radiative properties.

- The combustion gases generated from the fire are assumed to be semi-transparent. The interior surface of the shaft is isothermal, gray body for radiative heat transfer, diffuse and opaque.

- Pressure drops across the openings are considered, but the temperature changes through the openings are not included.

- The fire floor is taken as the first floor, and the opening areas are uniformly distributed along the height of shaft including at the fire floor. The cold fresh air below the fire floor entering the shaft does not mix up with the combustion gases.

- The pressure profile has a hydrostatic distribution in the shaft. The pressure drops due to the friction losses are neglected.

- There is a vent to atmosphere on the top of the shaft and the wind velocity is assumed to be zero in the calculations.

\subsection{Model Geometry}

The building geometry described in the mathematic model is shown schematically in Fig.1. The fire is located on the first floor. The construction opening and leaks around doors are uniformly distributed from bottom to the top of the building. The mathematic model stated above is developed based conservation of mass and energy for the smoke inside elevator shaft, and mass conservation for each floor, which are shown in Fig. 2 and Fig.3.

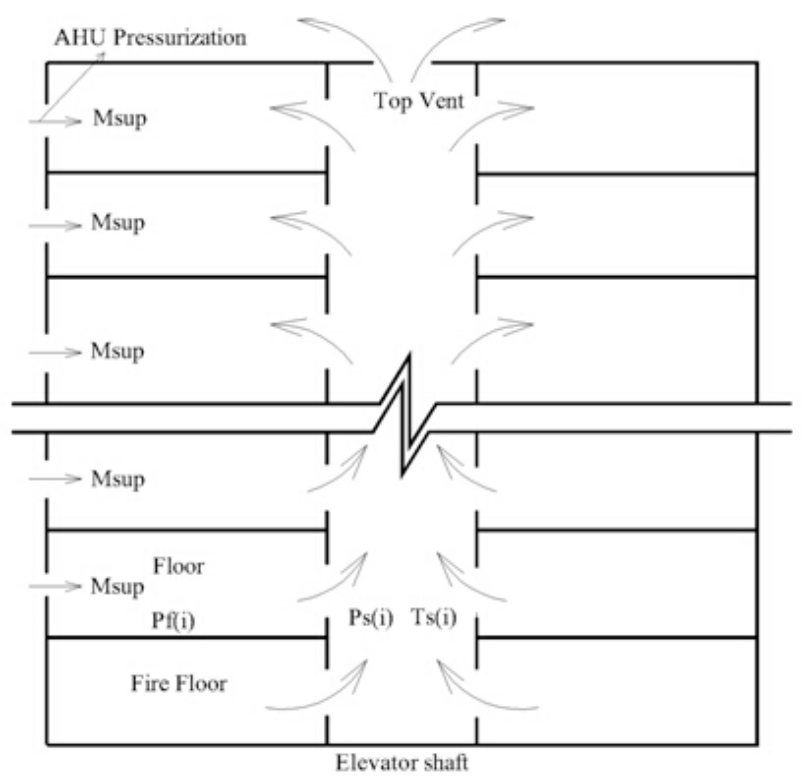

Fig.1. Schematic Diagram of Structure and Elevator Shaft

\subsection{Fire Models}

The two-layered zone model is used to predict the fire growth and smoke movement in multi-storey buildings, which is typically used in CFAST. The description about two-layered zone model is detailed elsewhere [6]. Here is a brief summary. The differential equations for the gas pressure, volume of upper layer gas, temperature of upper layer gas and lower layer one, are described as follows:

$$
\begin{aligned}
& \frac{d P}{d t}=\frac{\gamma-1}{V}\left(S_{U}+S_{L}\right) \\
& \frac{d V_{U}}{d t}=\frac{1}{\gamma P}\left((\gamma-1) S_{U}-V_{U} \frac{d P}{d t}\right) \\
& \frac{d T_{U}}{d t}=\frac{1}{C_{p} \cdot \rho_{u} V_{U}}\left[\left(S_{U}-C_{p} \cdot M_{U} \cdot T_{U}\right)+V_{U} \frac{d P}{d t}\right) \\
& \frac{d T_{L}}{d t}=\frac{1}{C_{p} \cdot \rho_{L} V_{L}}\left[\left(S_{L}-C_{p} \cdot M_{L} \cdot T_{L}\right)+V_{L} \frac{d P}{d t}\right)
\end{aligned}
$$

where $V_{U}$ and $T_{U}$ are the gas volume and temperature of the upper layer respectively, $\mathrm{V}_{\mathrm{L}}$ and $\mathrm{T}_{\mathrm{L}}$ are the gas volume and temperature of the lower layer respectively, SU and SL are the source items in the upper and lower gas layer respectively, $\mathrm{P}$ is the pressure in the fire room, $\gamma$ is the ratio of heat capacity and $\mathrm{V}$ is the volume of the fire room. The combustion model includes a heat release rate model, for example the constant fire and $\mathrm{t}^{2}$ fire, the fluid flow submodels, such as the McCaffrey's, Heskestad's, Zukoski's and Thomas-Hinkley's model, and so on, which are not described in details in this paper [22, 23]. Particularly, the constant fire and McCaffrey's plume model are selected in this paper, in which $\mathrm{Q} 0=5000 \mathrm{~kW}$ and the plume mass flow is:

$$
M_{p}=\left\{\begin{array}{rr}
0.011 \cdot\left(\frac{z}{Q_{c}^{2 / 5}}\right)^{0.566} \cdot Q_{c} & 0 \leq \frac{z}{Q_{c}^{2 / 5}}<0.08 \\
0.026 \cdot\left(\frac{z}{Q_{c}^{2 / 5}}\right)^{0.909} \cdot Q_{c} & 0.08 \leq \frac{z}{Q_{c}^{2 / 5}}<0.20 \\
0.124 \cdot\left(\frac{z}{Q_{c}^{2 / 5}}\right)^{0.909} \cdot Q_{c} & 0.20 \leq \frac{z}{Q_{c}^{2 / 5}}
\end{array}\right.
$$

where $M_{\mathrm{p}}$ is the mass flow rate of the plume generated from the fire, $Q_{\mathrm{c}}$ is the convective heat release rate, about 70 percents of the total heat release rate, and $\mathrm{z}$ is the elevation height above the fire source.

The method of weighting average is adopted for the junction surface between the two-layered zone and the network model. The average temperature from two-layered zone into the network region is expressed as follows:

$$
T_{A V}=\frac{T_{U} \cdot(H-Z)+T_{L} \cdot Z}{H}
$$

Where $Z$ is the interface height between the upper and lower layers, and $H$ is the height of the room on fire.

\subsection{Governing Equations}

Like other smoke control models, such as field model and zone model, the principle equations for each horizontal layer 
are derived from the conservation equations of mass and energy.

As the flow rises through the vertical shaft as results of stack effect and buoyancy effect, the hot heavy smoke mixes up with cold fresh air or exits the shaft, which depends on the sign of $\mathrm{M}_{\mathrm{as}}(\mathrm{i})$ shown in Fig.2. The equation for the $i$-th gas layer in the shaft can be expressed as follows:

$$
M_{s}(i)=M_{s}(i-1)+M_{f s}(i)
$$

Where $\mathrm{M}_{\mathrm{s}}(\mathrm{i})$ and $\mathrm{M}_{\mathrm{s}}(\mathrm{i}-1)$ are the smoke mass flow rates of $i$ th $(1<\mathrm{i} \leq \mathrm{N})$ and $i$-1-th layer in the shaft, respectively, $\mathrm{M}_{\mathrm{fs}}(\mathrm{i})$ is the mass flow rate due to the door gaps and opening area of building materials, ' + ' indicating cold fresh air flows in and '-" indicating hot smoke exits the shaft.

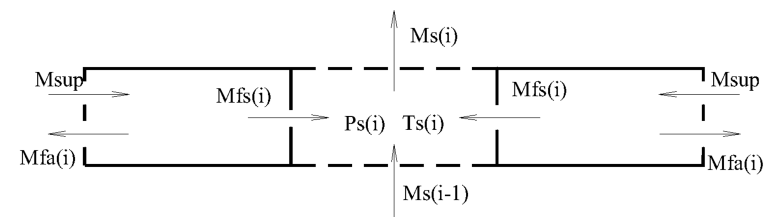

Fig.2. Mass conservation of the $i$-th layer in the structure $(1<\mathrm{i} \leq \mathrm{N})$

Considered the 1st layer in the shaft being connected with the fire floor, the conservation of mass is written as:

$$
M_{s}(1)=M_{p s}
$$

where $M_{\mathrm{ps}}$ is the hot smoke entering the shaft through elevator doors on the fire floor.

In a similar way, the mass conservation for the $i$-th floor can be impressed by equation (9).

$$
M_{\text {sup }}=M_{f s}(i)+M_{f a}(i)
$$

Where $M_{\text {sup }}$ is the air mass flow rate provided with AHUs, $M_{\mathrm{fa}}(\mathrm{i})$ is the mass flow rates from the floors to the environment due to the opening area of building materials $(1 \leq \mathrm{i} \leq \mathrm{N})$.

One of the improvements made in this new model is to consider heat transfer between the gas layers and the shaft surfaces, which is essential for the smoke control analysis. The gas temperature distribution profile can be developed by solving the energy conservation equations, which provides more accurate results than an assumed uniform temperature profile. According to Fig.2, the conservation of energy equation applied to the $i$-th $(1<\mathrm{i} \leq \mathrm{N})$ gas layer and the $i$-th $(1 \leq i \leq N)$ surface element in the vertical shaft is expressed as follows, respectively.

$$
\begin{aligned}
& 4 k_{a} \sigma d V T_{s}^{4}(i)+M_{s}(i) C_{p} T_{s}(i)+h d A \cdot\left(T_{s}(i)-T_{w}\right) \\
& =4 k_{a} \sigma \sum_{j} \operatorname{Rgg}(j, i) T_{s}^{4}(i)+\varepsilon_{w} \sigma d A \sum_{j} \operatorname{Rwg}(j, i) T_{w}^{4} \\
& +M_{s}(i-1) \cdot C_{p} \cdot T_{s}(i-1)+M_{f s}(i) \cdot C_{p} \cdot \\
& {\left[\delta\left(P_{f}(i), P_{s}(i)\right) \cdot T_{a}(i)+\left(1-\delta\left(P_{f}(i), P_{s}(i)\right) \cdot T_{s}(i)\right)\right]}
\end{aligned}
$$

$$
\begin{aligned}
& \varepsilon_{w} \sigma \cdot d A \cdot T_{w}^{4}+Q_{w}(i) \cdot d A=4 k_{a} \sigma d V . \\
& \sum_{j} R g w(j, i) T_{s}^{4}(i)+\varepsilon_{w} \sigma d A \sum_{j} R w w(j, i) T_{w}^{4}
\end{aligned}
$$

$+h \cdot d A \cdot\left(T_{s}(i)-T_{w}\right)$

For the $1^{\text {st }}$ gas layer, the conservation of energy is: $4 k_{a} \sigma d V T_{s}^{4}(1)+M_{s}(1) C_{p} T_{s}(i)+h d A\left(T_{s}(1)-T_{w}\right)$

$$
\begin{aligned}
& =4 k_{a} \sigma \sum_{j} \operatorname{Rgg}(j, 1) T_{s}^{4}(1)+\varepsilon_{w} \sigma d A \sum_{j} \operatorname{Rwg}(j, 1) T_{w}^{4} \\
& +M_{p s} C_{p} T_{A V}+M_{f s}(1) C_{p}\left[\delta\left(P_{f}(1), P_{s}(1)\right) \cdot T_{a}(1)\right. \\
& \left.+\left(1-\delta\left(P_{f}(1), P_{s}(1)\right) \cdot T_{s}(1)\right)\right]
\end{aligned}
$$

Where $\operatorname{Rgg}(i, j), \operatorname{Rgw}(i, j), \operatorname{Rwg}(i, j)$ and $\operatorname{Rww}(i, j)$ are the radiation energy absorption distribution coefficient stated later in this paper, $\delta(i, j)$ is a judgment function:

$$
\delta(i, j)=\left\{\begin{array}{l}
1, i \geq j \\
0, i<j
\end{array}\right.
$$

The item $Q_{w}(i)$ in Eq. (11) is the thermal heat flux absorbed by the $i$-th shaft surface, which can decrease the smoke temperature as rising upward inside the shaft. Eqs. (10), (11) and (12) keep the balance of energy flowing in and out for each gas layer and each surface element. The energy conservation accommodates the cold fresh air infiltration which can mix with the smoke in the shaft.

The constant coefficients $d V$ and $d A$ are expressed as follows, respectively.

$d V=L \cdot W \cdot H$

$d A=2 \cdot(L+W) \cdot H$

\subsection{Auxiliary equations}

Eqs. (10), (11) and (12) can be integrated for each layer using both Levenberg-Marquardt Method for gas temperature and Eq. (7) using Newton-Rampson Method for gas pressures in shaft. In order to solve these equations, the rate terms in the equations need to be modeled as well based on heat transfer and fluid mechanics for each component. These models are presented as the following.

\subsubsection{Heat transfer model}

As mentioned earlier, the convective heat flux to the surface is quantified by a combination of natural and forced convection correlations.

$$
Q_{\text {conv }}=h \cdot d A \cdot \Delta T
$$

where $Q_{\text {conv }}$ is the convective heat transfer of each layer; $d A$ is the surface area of each layer; $\Delta T$ is the temperature difference between the combustion gas and the shaft wall; $h$ is the combined convective heat transfer coefficient, which is calculated as follows:

$$
\begin{aligned}
& h=\max \left(h_{n}, h_{f}\right)=\max \left[C_{1} \cdot|\Delta T|^{1 / 3},\right. \\
& \left.\frac{k_{c}}{D_{h}} \cdot C_{2} \cdot \operatorname{Re}^{4 / 5} \cdot \operatorname{Pr}^{1 / 3}\right]
\end{aligned}
$$


where $C_{l}$ is the coefficient for natural convection (1.52 for a horizontal surface and 1.31 for a vertical surface) and $C_{2}$ is the coefficient for forced convection, equaling $0.037 ; D_{h}$ is a characteristic length related to the size of the physical obstruction; $k_{c}$ is the thermal conductivity of the gas, and the Reynolds and Prandtl numbers are based on the gas flowing past the obstruction. The Reynolds number is defined as:

$\operatorname{Re}=V_{s} \cdot D_{h} / v$

Where $v$ is the kinematic viscosity of the gas; $V_{s}$ is the velocity in the shaft, calculated as $V_{s}=M_{s} / A_{x}$, in which $A_{x}$ is the cross area of shaft, $\mathrm{A}_{\mathrm{x}}=\mathrm{W} \times \mathrm{L}, D_{h}$ is the hydraulic diameter representing the rectangular shaft defined as:

$D_{h}=\frac{4 \cdot A_{x}}{p}=\frac{2 W \cdot L}{W+L}$

\subsubsection{Heat transfer model}

The radiative heat transfer analysis is complicated due to the fact that the gases in the shaft are semi-transparent. Radiation leaving at an arbitrary layer is partially absorbed by adjacent layers before it reaches the solid surface of the shaft. The Radiation Energy Absorption Distributions (READ) method, a modified form of Monte-Carlo Method, is considered here to calculate the radiant energy transferred among the layers and the shaft surfaces [24]. The value of $\operatorname{Rgg}(i, j), \operatorname{Rgw}(i, j), \operatorname{Rwg}(i, j)$ and $\operatorname{Rww}(i, j)$ are the coefficients presented in READ method. The quantity of $\operatorname{Rgg}(i, j)$ indicates the energy absorbed by the $i$-th gas layer radiating from the $j$-th gas layer, the $\operatorname{Rgw}(i, j)$ indicates the energy absorbed by the $i$-th shaft surface element radiating from the $j$-th gas layer, the $\operatorname{Rwg}(i, j)$ indicates the energy absorbed by the $i$-th gas layer radiating from the $j$-th shaft surface element, and the $\operatorname{Rww}(i, j)$ indicates the energy absorbed by the $i$-th shaft surface element radiating from the $j$-th shaft surface element. According to the statements above, the following expression can be achieved:

$\sum_{j}[\operatorname{Rgg}(j, i)+\operatorname{Rg} w(j, i)]=1.0$

$\sum_{j}[R w g(j, i)+R w w(j, i)]=1.0$

Obviously, the quantity of $\operatorname{Rgg}(i, j), \operatorname{Rgw}(i, j), \operatorname{Rwg}(i, j)$ and $R w w(i, j)$ include the energy absorbed by itself, and they are calculated using Monte-Carlo Method, in which the tracing of radiation beam is shown in Fig.3 [25]. From Fig.3, the tracing processes of radiation beam, four courses including $\mathrm{I} \rightarrow \mathrm{A}, \mathrm{I} \rightarrow \mathrm{B}, \mathrm{I} \rightarrow \mathrm{C}$ and $\mathrm{I} \rightarrow \mathrm{D}$, are clearly presented. The processes lead to the facts that the radiation energy for the I-th layer are absorbed by some gas layer, some shaft surface, reflected by one surface and absorbed by another surface, reflected by one surface and absorbed by some gas layer, respectively. The radiation beam is traced until it is completely absorbed.

As we can see from the equations, the quantities of $\operatorname{Rgg}(i$, $j), \operatorname{Rgw}(i, j), \operatorname{Rwg}(i, j)$ and $R w w(i, j)$ can be solved for a typical vertical shaft structure, despite of the changes of gas properties. This process leads to less computation time.

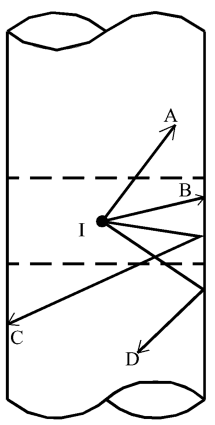

Fig.3. The demonstration of tracing radiation beam

\subsubsection{Fluid mechanics considerations}

In this model, the effect of wind on building pressure is neglected. As the hot smoke rises upward in the shaft, the cold air or the hot smoke may pass through the opening and gaps around doors due to the pressure drop between the shaft and outside at the same height of the $i$-th layer. The mass flow rate can be calculated as:

$$
\begin{aligned}
& M_{f s}=C_{D} \sqrt{2 \rho_{a} \cdot\left(P_{f}-P_{s}\right)}\left(\mathrm{P}_{\mathrm{f}} \geqslant \mathrm{P}_{\mathrm{s}}\right) \\
& M_{f s}=C_{D} \sqrt{2 \rho_{s} \cdot\left(P_{s}-P_{f}\right)}\left(\mathrm{P}_{\mathrm{f}}<\mathrm{P}_{\mathrm{s}}\right)
\end{aligned}
$$

Here $C_{D}$ is the discharge coefficient of the opening, 0.6 by default. Eqs. (22) and (23) can be transformed into the expressions as follows for the convenience of calculation,

$$
\begin{aligned}
& M_{f s}=\operatorname{sign}\left(P_{f}-P_{s}\right) \cdot C_{D} \cdot \\
& \sqrt{2 \cdot\left[\delta\left(P_{f}, P_{s}\right) \rho_{a}+\left(1-\delta\left(P_{f}, P_{s}\right)\right) \rho_{s}\right] \cdot\left|P_{f}-P_{s}\right|}
\end{aligned}
$$

where $\operatorname{sign}(x, y)$ is the symbolic function:

$$
\operatorname{sign}(x, y)=\left\{\begin{array}{l}
+x \geq y \\
-x<y
\end{array}\right.
$$

The ambient pressure and temperature above the top of the building are characterized in this model as follows, respectively,

$$
\begin{aligned}
& T_{a}\left(Z_{i}\right)=T_{a 0}-0.0065 \cdot Z_{i} \\
& P_{a}\left(Z_{i}\right)=P_{a 0}\left[\frac{T_{a}\left(Z_{i}\right)}{T_{a 0}}\right]^{5.26}
\end{aligned}
$$

Here $Z_{i}$ is the mean height of the $i$-th gas layer. The pressure differences across the openings decide the flow direction, viz. the sign of $\mathrm{M}_{\mathrm{as}}(\mathrm{i})$.

The pressure of each layer in the shaft has a hydrostatic profile which is defined as:

$$
P_{s}(i)=P_{s}(i-1)-\rho_{s}(i-1) \cdot g \cdot d Z
$$

where $\mathrm{P}_{\mathrm{s}}(i), \rho_{\mathrm{s}}(i)$ are the gas pressure and density of the $i$-th $(1<i \leq \mathrm{N})$ gas layer, respectively, $d Z$ is the thickness of layers. The gases are considered to be ideal gases, we can get:

$P_{s}=\rho_{s} \cdot R \cdot T_{s}$ 
Thus the density of gas is described as follows:

$$
\rho_{s}=P_{s} /\left(R \cdot T_{s}\right)
$$

Eq. (28) includes the shaft pressure noted by $\mathrm{P}_{\mathrm{s}}(i)$ at the 1 st gas layer. The equation can be solved using NewtonRampson Method, starting from an initial value of $\mathrm{P}_{\mathrm{s}}(1)$ and calculate the pressures of other layers, viz. $\mathrm{P}_{\mathrm{s}}(i)$ under the conditions of the known gas temperatures in the shaft.

\section{Experimental Design and Instrumentation}

\subsection{Experimental apparatus}

A fairly versatile experimental system has been designed and fabricated. The schematic diagram and full photograph views of the experiment system are shown in Fig.4 and Fig.5, respectively. The shaft is $1.50 \mathrm{~m}$ height by $0.10 \mathrm{~m}$ long by $0.20 \mathrm{~m}$ width, and the antechamber has a size of $0.20 \mathrm{~m}$ long by $0.20 \mathrm{~m}$ width by $0.20 \mathrm{~m}$ height. The ten thermocouples are positioned uniformly in the centerline of the vertical shaft, with $0.15 \mathrm{~m}$ spacing.

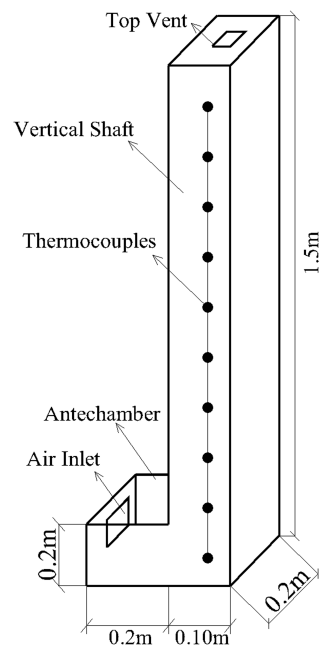

Fig.4. Sketch of the experimental apparatus

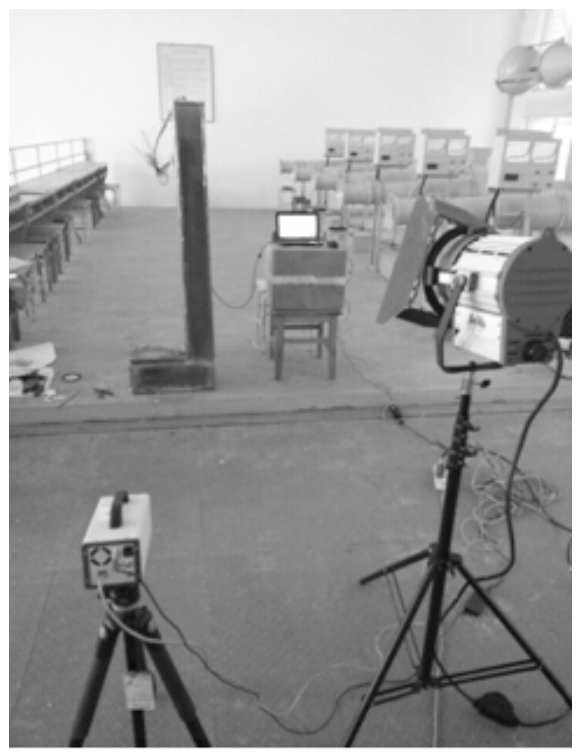

Fig.5. Photograph full view of the experimental system
The experiment system is made of steel metal sheet insulated with fiberglass except one side of fire-resistant glasses allowing for visualization of flow. For a typical 15storey building, this represents an approximately $1 / 30$ scale model. The ethanol pool is positioned in the center of the antechamber floor. The fire is burned with natural air makeup, where the air inlet is on the left side of antechamber indicated in Fig.4. The upstream velocity and temperature distributions are measured by means of hot-wire anemometers and thermocouples. The hot-wire anemometers and the thermocouples are both calibrated at different values by standard air velocity and water baths., with the accuracy of $0.1{ }^{\circ} \mathrm{C}$ and $0.1 \mathrm{~m} / \mathrm{s}$, respectively. The data acquisition system is employed for obtaining the actual values of the local temperature every one second. The ethanol pool is placed in the center of shaft lobby, with the mass quantity of about $50 \mathrm{mg}$.

\subsection{Experiment results}

The data obtained from the experiment system, the FDS and the simplified model, are plotted in Fig.6. The top vent area ratio is defined as $10 \%, 30 \%$ and $50 \%$ of the shaft crosssection, and the environment temperature was about $35^{\circ} \mathrm{C}$. The average temperature is calculated as the mean value of data measured by thermocouples in the shaft. FDS software is used to simulate the model shaft. The smoke mass flow into the shaft obtained from the experiment and FDS simulation outputs are used as input parameter in the simplified model.

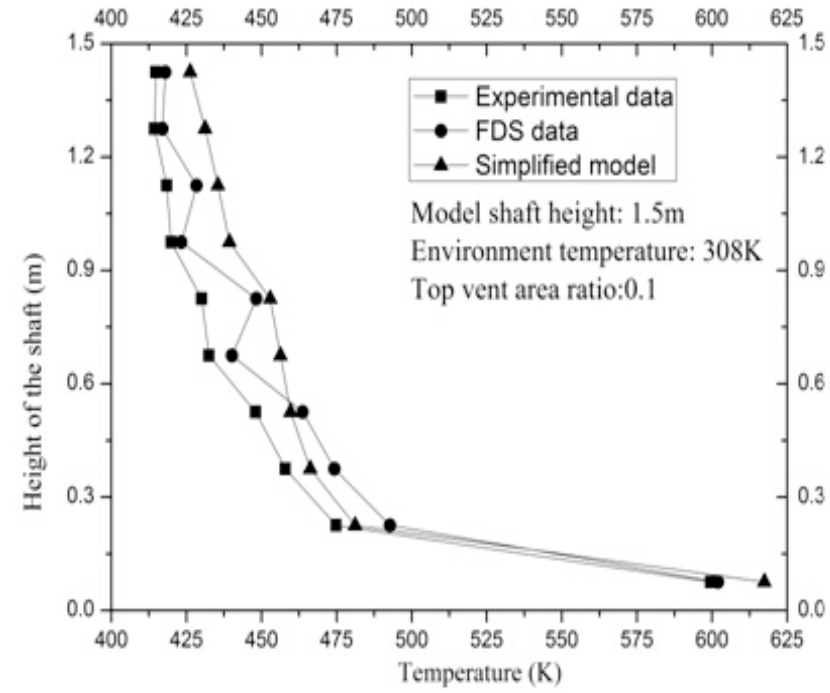

Fig.6. Smoke temperature profiles in the model shaft

The optimistic conclusions with almost the same trends can be drawn based on the curves shown in Fig.6. The maximum absolute value of temperature difference is less than $20 \mathrm{~K}$. For the limited spaces of this paper, the other data for top vent area ration 0.3 and 0.5 are not presented.

\section{Results and discussions}

The results are generated by solving the governing equations and the sub models as stated above for a 30 -storey, $1500 \mathrm{~m}^{2}$ structure that has a single elevator shaft with four cars. A 
summary of the input parameters is listed in Table 1 . It needs to mention that some variables are simplified for the convenient of calculations and some changes may lead to different output for the smoke movement. The patterns of the results instead of the absolute values are the focuses of this study, as obtained from the conditions specified in Table.1. In the real implementation, a comprehensive smoke control plan need to be integrated with sound judgment and engineering experience.

The input variables to specify the smoke control program are complex and the number of combinations is exceedingly large. Results for other variables, such as the building exterior surface, the shaft constructions and stairwell pressurization, will be considered in the subsequent papers. In the generated results for the selected cases, the location of NPP and the gas mass flow rate are taken into account particularly. The average values of steady-state results are selected and presented in the following figures.

\subsection{Position of elevator doors on the fire floor}

The smoke mass flow inside the shaft is plotted in Fig.7, where the NPP is located at the elevation of the maximum mass flow rate. Below the NPP, the smoke is entering the elevator shaft from the floors. Above the NPP, the direction of flow is reversed. As a result, the hot smoke is forced out of the shaft into the floors to produce potentially dangerous environment for the occupants. Therefore, the location of NPP is of vital importance for the smoke control during high-rise fires. This leads to a concept that the improvement of NPP can improve the safety of occupants on the upper floors. The location of NPP is decreased from $18^{\text {th }}$ floor to $16^{\text {th }}$ floor without and with elevator doors open, as can be seen from Fig.7. The calculated results with a single, two and three doors open on the fire floors are basically identical for which the curves are overlapped for the pressure, mass flow rate of smoke, and temperature distributions. This indicates that the opening area with a single elevator door open is large enough for the management of smoke and the additional open elevator doors have little effects. In other words, it is feasible for smoke flow with a single elevator door open.

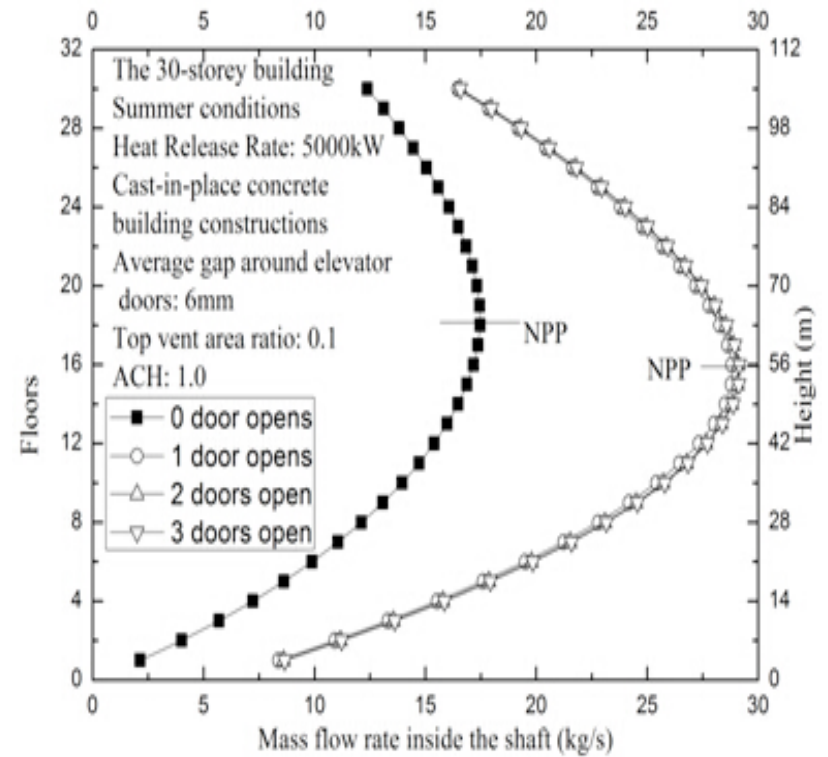

Fig.7. Mass flow rate inside shaft with and without doors open
Table 1 Input conditions for the mathematic model

\begin{tabular}{|c|c|}
\hline Input variables & Value \\
\hline \multicolumn{2}{|l|}{ Atmospheric conditions } \\
\hline $\begin{array}{l}\text { Atmospheric temperature at } \\
\text { oround level }\end{array}$ & 35 (summer conditions) \\
\hline $\begin{array}{l}\text { Atmospheric pressure at } \\
\text { ground level }\end{array}$ & $101.3 \mathrm{kPa}$ \\
\hline Wind velocity & $0 \mathrm{~m} / \mathrm{s}$ \\
\hline \multicolumn{2}{|l|}{ Fire conditions } \\
\hline Heat release rate & $5000 \mathrm{~kW}$ \\
\hline Fire floor & $1^{\text {st }}$ floor \\
\hline $\begin{array}{l}\text { Absorption coefficient of } \\
\text { combustion gas }\end{array}$ & $0.1 \mathrm{~m}^{-1}$ \\
\hline $\begin{array}{l}\text { Thermal conductivity of } \\
\text { combustion oas }\end{array}$ & $5.0 \times 10^{-2} \mathrm{~W} / \mathrm{m}^{2} \mathrm{~K}$ \\
\hline Simulation time & $2400 s$ \\
\hline Time interval & $10.0 \mathrm{~s}$ \\
\hline \multicolumn{2}{|l|}{ Building constructions } \\
\hline Building height & 30 -storey \\
\hline Height of each floor & $3.5 \mathrm{~m}$ \\
\hline Floor area of each floor & $1500 \mathrm{~m}^{2}$ \\
\hline $\begin{array}{l}\text { Area ration of openings in } \\
\text { the exterior surface }\end{array}$ & $\begin{array}{l}1.8 \times 10^{-4} \mathrm{~m}^{2} / \mathrm{m}^{2} \quad \text { (cast-in-place } \\
\text { concrete) }\end{array}$ \\
\hline $\begin{array}{l}\text { Elevator } \\
\text { constructions }\end{array}$ & \\
\hline Number of elevator cars & 4 \\
\hline Gaps around elevator doors ${ }^{1}$ & $3 \sim 18 \mathrm{~mm}$ \\
\hline Cross area of elevator shaft & $16.0 \mathrm{~m}^{2}$ \\
\hline $\begin{array}{l}\text { Vent size on top of elevator } \\
\text { shaft }^{1}\end{array}$ & $\begin{array}{l}0.56 \mathrm{~m}^{2}, 1.6 \mathrm{~m}^{2}, 3.2 \mathrm{~m}^{2}, 4.8 \mathrm{~m}^{2}, \\
6.4 \mathrm{~m}^{2}(3.5 \%, 10 \%, 20 \%, 30 \% \text {, } \\
40 \% \text { of shaft area, respectively) }\end{array}$ \\
\hline $\begin{array}{l}\text { Height and width of each } \\
\text { elevator door }\end{array}$ & $2.2 \mathrm{~m} \times 1.2 \mathrm{~m}$ \\
\hline Interior surface temperature & 50 \\
\hline $\begin{array}{l}\text { Absorptivity of elevator shaft } \\
\text { surface }\end{array}$ & 0.3 \\
\hline $\begin{array}{l}\text { Emissivity of elevator shaft } \\
\text { surface }\end{array}$ & 0.3 \\
\hline AHU conditions & \\
\hline
\end{tabular}

The smoke inside the vertical elevator shaft is driven by buoyancy forces that are predominately determined by the local gas temperature, which is shown in Fig.8. When no elevator doors are open, the hot smoke infiltrates into the shaft through the gaps around elevator doors and through opening area of the shaft construction at the fire floor. The mass flow rate of smoke is less. The smoke $t$ is cooled by the cold air and the shaft surface dramatically. The cooling is sufficient to ensure gas temperature nearly dropped to the shaft surface temperature by the time the smoke reaches the $12^{\text {th }}$ floor. When a single elevator door on the fire floor is open, more smoke enter the shaft. The smoke temperature gradually decreases as it transfers energy to the shaft surface and is cooled by the ambient air. 


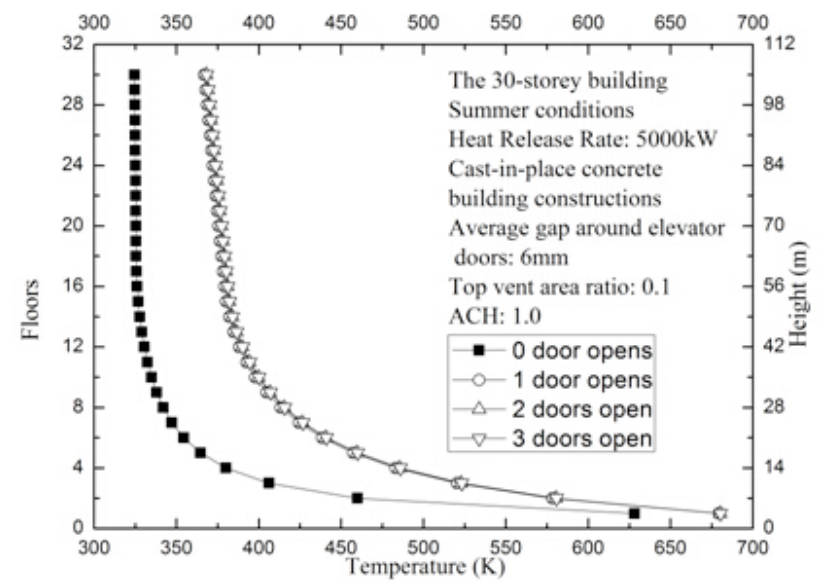

Fig.8. Temperature distributions inside the elevator shaft

Since the temperature difference is the mechanism for the buoyancy-driven fluid flows including the smoke movement in the elevator shaft, the assumptions of isothermal smoke or specific distribution in the shaft could lead to large errors in the results. Both convective and radiative heat transfer are included in the model, which are not considered in most of other software packages.

\subsection{Top vent area}

The influences of top vent size are quantified and shown in Fig.9, which plot the total mass flow rate inside the elevator shaft as the vent area ration is changed with no doors open. The cases used in this figure are similar to those used in Fig.7.

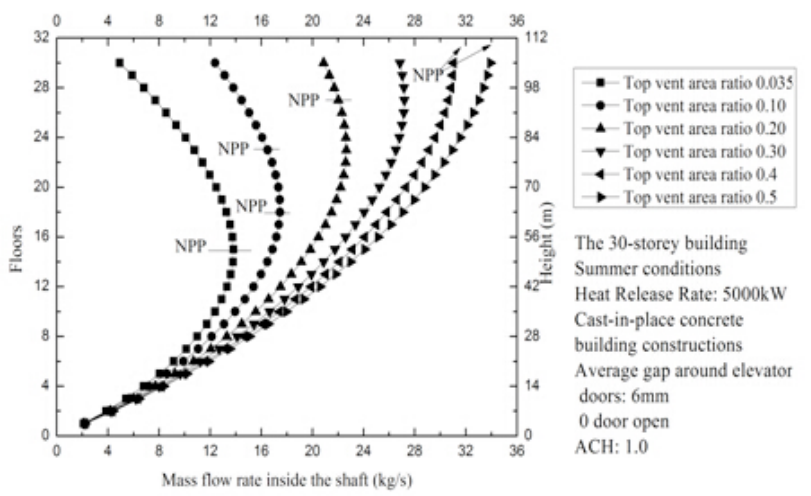

Fig.9. Mass flow rate inside shaft with variable top vent sizes

The minimum vent size required by the building codes is $3.5 \%$ of the shaft cross-section area [26]. Increasing the top vent size) to $50 \%$ of the shaft cross-section area can enhance the total mass flow rate through the vent. By changing the top vent size from $3.5 \%$, to $10 \%, 20 \%$ and $30 \%$ of the shaft area with no door open; the NPP is raised from the 15th to the 19th, 23rd and 27th floors, respectively. The NPP is above the maximum height of the building with the top vent size of $40 \%$ and $50 \%$, which can be seen from Fig.9.

The influences of top vent size on the mass flow rate out of the shaft and the location of NPP are shown in Fig.10 with two scenarios of no door open and a single door open. The location of NPP is raised above the total height of structure and $40 \%, 50 \%$ of top vent area ratio with no doors open, which are not presented in this figure. The smoke mass flow rate out of the shaft is increased with the increasing top vent size; however, the changing rate is gradually slowing down.
No smoke contaminates the upper floors once the NPP is above the maximum height of structure. This indicates that increasing the size of the top vent can achieve smoke-free conditions on the upper floors. The smaller top vent size has higher chances of smoke entering the occupied areas from the shaft. In addition, changing the top vent size is more effective for the case with no elevator doors open than the one with a single elevator door open. Thus, a moderate increase on the size of top vent can have a profound influence on the fire safety plan during high-rise fires.

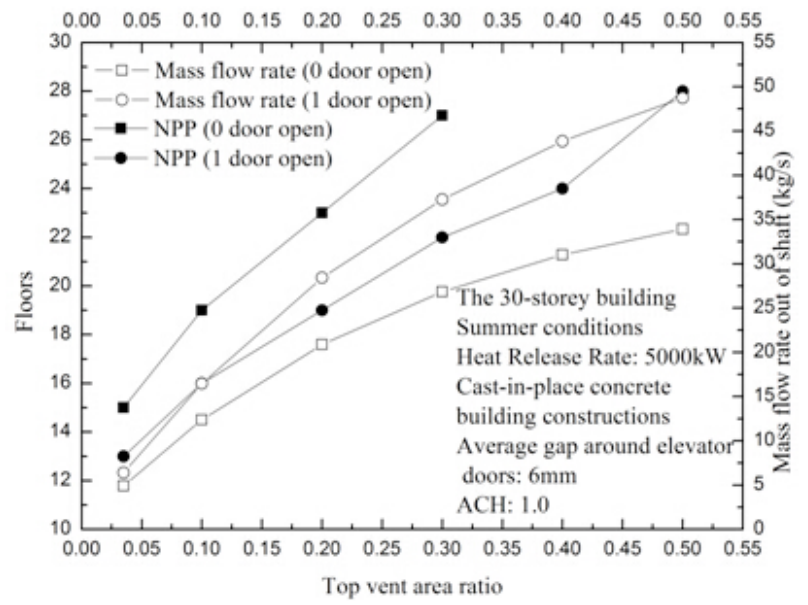

Fig.10. Changes of the NPP locations and mass flow rate with variable top vent sizes

Clearly, the tightness of the building structure can affect the smoke movement path during the fire. A relatively airtight structure tends to contain the smoke inside of the vertical shaft. The effects of tightness of building structure, the elevator shaft constructions and the wind velocity, and so on, will be presented in the following sections using the simplified model.

\subsection{Tightness of elevator doors}

The tightness of elevator doors has an influence on the quantity of the smoke that enters or leaves the vertical shaft during a fire. The smoke mass flow rate inside the shaft with no doors open as a function of the shaft height is plotted in Fig.11.

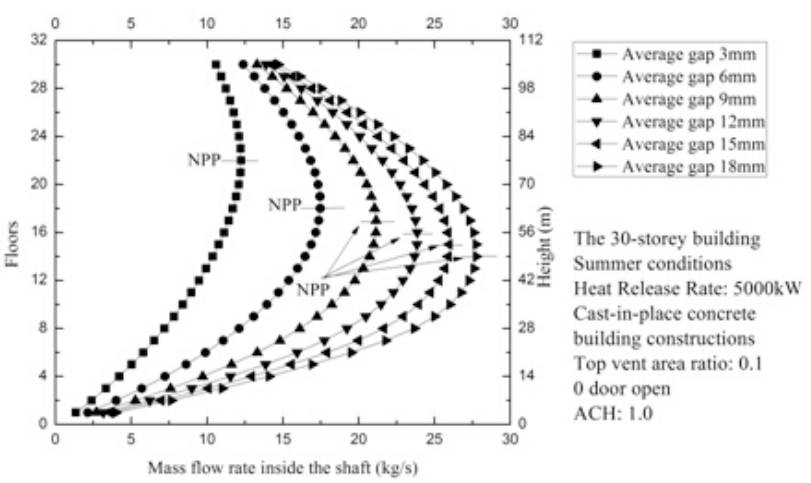

Fig.11. Mass flow rate inside shaft with variable door gaps

Fig. 11 shows that the location of NPP lowered from $22^{\text {nd }}$ floor to $14^{\text {th }}$ floor, and the changes of the mass flow rate are slightly enhanced when the gap around elevator doors increases from $3 \mathrm{~mm}$ to $18 \mathrm{~mm}$. The results indicate that the 
gaps around doors have minor impacts on the location of NPP and smoke mass flow between the shaft and floors with no elevator doors open.

The smaller is the gap around elevator doors, the higher is the location of NPP of the vertical shaft. On the other hand, if the elevator door fits loosely, the NPP is reduced and more smoke could enter the upper floors. By comparing the effects of top vent size or the position of elevator door on the fire floor, the impact of gap size around elevator doors can be neglected.

The influences of gap around elevator doors on the smoke mass flow rate out of the shaft and the location of NPP are shown in Fig.12. The location of NPP is lowered as the average gap around elevator doors is increasing, where the tendency is more remarkable with no doors open. The location of NPP becomes equal when the gap is increased to $12 \mathrm{~mm}, 15 \mathrm{~mm}$ and $18 \mathrm{~mm}$, with a single elevator door open. As for the smoke mass flow rate out of the shaft, the quantity of smoke delivered is also the same with a single door open, and it is gradually improved as the average gap is increasing, however, the tendency is slower.

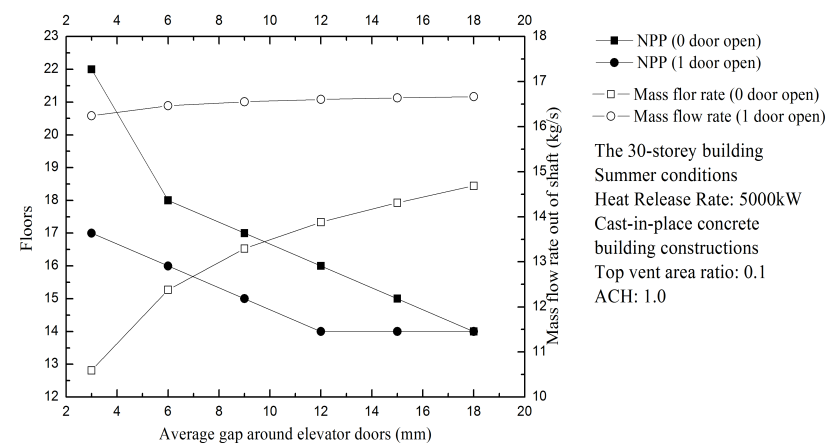

Fig.12. Changes of the NPP and mass flow rate out of the shaft with variable door gaps

The results extracted from the two set of curves in Fig.12 indicate that the average gaps around elevator doors have minor effects on the NPP and the smoke delivered through the shaft with a single elevator door open. Changes of gaps around elevator doors are not nearly as influential in changing the smoke movement as changing the area of top vent. While the size of the top vent can be easily varied, the changes in the gap around the doors are difficult in practice.

\subsection{Floor pressurization using AHUs}

As mentioned above, the higher is the position of NPP, the easier it is to prevent the hot smoke from leaving the vertical shaft and to improve the occupant safety. One practical way to raise the NPP is to pressurize the floors above the fire floor, where the dedicated make-up air fans or the AHUs supply fans can be utilized. The return duct dampers are fully closed and the fresh air dampers are full open, which can be triggered by a smoke alarm or the sprinkler system during high-rise fires. The quantity of air volume flow rate used in this paper is in the range of $0-3 \mathrm{ACH}$, which is feasible for the current AHUs.

The gas mass flow rate at each floor with no doors open is shown in Fig.13. The negative mass flow rate at each floor indicates that the smoke exiting the shaft and vice versa. The vertical straight line in the figure, viz. $\mathrm{M}_{0}$, indicates that the quantity of mass flow rate at each floor equal to zero, and the line intersects with the other curves at the elevation where the NPP is located. Fig. 13 shows that the location of NPP is raised from $17^{\text {th }}$ floor to $18^{\text {th }}, 21^{\text {st }}$ and $25^{\text {th }}$ floors with $\mathrm{ACH}$ ranging from 0 to 2.0. When the quantity of $\mathrm{ACH}$ is at 2.5 or 3.0 , the location of NPP is above the total height of building. The results indicate that floor pressurization has a sizable impact on the location of NPP and the quantity of $\mathrm{ACH}$ is modest acceptable with the existing AHUs.

One note of caution should be mentioned that the presence of stairwells is ignored in the model. In fact, the stairwell pressurization is universally considered during a as the only safe escapes. The supply air can inevitably enter the floors due the pressure differences $(+25 \sim+87 \mathrm{~Pa}$, International Building Code 2009, Section 909.20.5) inside the stairwell shaft. Thus the air is pushed into the floors and it will increase the pressures preventing the smoke from coming in, whereas creates a safer environment. If the evacuation door between the stairwell and the fire floor is open, the pressure inside the stairwell shaft is decreased. This is a more complicated condition and not presented in this paper.

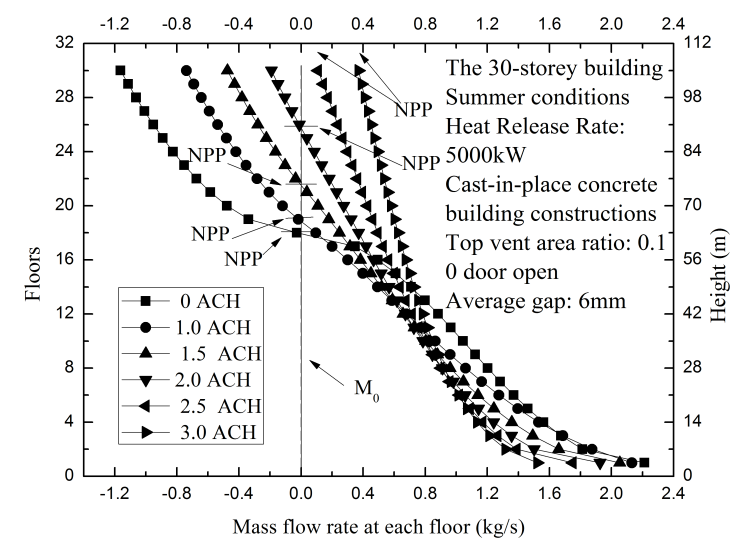

Fig.13. Effects of floor pressurization capacity with different $\mathrm{ACH}$

Fig.14 shows the location of NPP and mass flow rate out of the shaft as a function of ACH on each floor. For low air flow rate supplied, the location of NPP is raised very slowly, and to a lesser degree, the pressure inside the elevator shaft is increased. However, once the air flow rate is increased further, the NPP is pushed to higher floors with a modest $\mathrm{ACH}$. For example, the location of NPP is at the $21^{\text {st }}$ floor with $1.0 \mathrm{ACH}$, and it is raised above the total height of structure with $2.0 \mathrm{ACH}$ with no elevator doors open. The smoke mass flow rate out of the shaft is basically changed linearly with $\mathrm{ACH}$, as is shown in Fig.14.

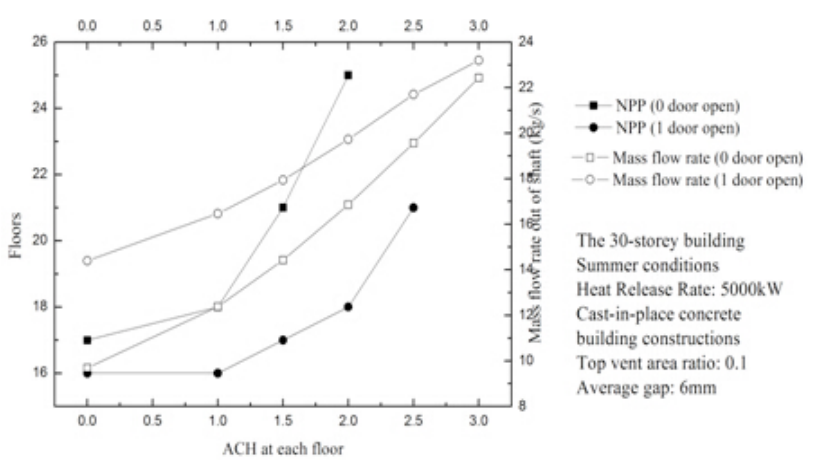

Fig.14. Changes of the NPP and mass flow rate out of shaft with different $\mathrm{ACH}$ 


\section{Conclusions}

A simplified model is developed by integrating a twolayered zonal model with a network model. Both convective and radiative heat transfer are considered in the simplified model. This model can predict the smoke movement in the vertical shaft, during a high-rise fire. The position of elevator doors is of vital importance, which determines the main path that the smoke will take in a fire. The mathematic models indicate pressurizing the floors above the fire floor can contain the smoke inside the shaft. The tightness of elevator doors and the vent size on the top of shaft are all considered as variables and analyzed. Cleary, the tighter elevator doors will raise the location of NPP to some extent. The $6.0 \mathrm{~mm}$ gap around elevator doors is nearly close to the actual conditions which is difficult to reduce further. The tightness of elevator doors has minor impacts on the location of NPP and the smoke mass flow rate out of the shaft.

A series of experiments are conducted with the simplified model for a typical 30 -storey building with a constant heat release rate of $5000 \mathrm{~kW}$. The results show that the top vent size and the quantity of air flow rate (ACH) greatly influence the smoke movement during high-rise fires, which is more obvious with no doors open than that with doors open on the fire floor.
Under the same conditions, increasing the top vent area size can result in a higher NPP location, ultimately above the building roof so no smoke can enter the upper floors. The required $\mathrm{ACH}$ to pressurize each floor above the fire floor is modest such that the quantity of existing AHUs could achieve. This will increase the pressure on each floor except the fire floor to prevent the smoke from infiltrating the floors during high-rise fires.

In summary, it is recommended to pressurize floors, increase top vent size and have tighter elevator doors so that location of NPP is higher with less or no smoke exiting the vertical shaft. These measures can be implemented in the smoke control system to improve occupant safety during high-rise fires.

\section{Acknowledgements}

Authors would like to acknowledge the financial support from "the Fundamental Research Funds for the Central Universities" (12MS114), "Special Funds for Excellent Doctoral Dissertation of Beijing" (20121007901), and "Program of Shanghai Center Building"(09dz1207704).

\section{References}

1. Yan Wang, George Hadiisophocleous, Elab Zalok. "Smoke movement in multi-storey buildings using CUsmoke", Safety Science, 52, 2013, pp.13-27

2. Hong Huang, Ryozo Ooka, Hong Chen, Shinsuke Kato. "Optimum design for smoke-control system in buildings considering robustness using CFD and Genetic Algorithms", Building and Environment, 44, 2009, pp. 2218-2227

3. W.K. Chow, S.S. Li, Y. Gao, C.L. Chow. "Numerical studies on atrium smoke movement and control with validation by field tests", Building and Environment, 44, 2009, pp.1150-1155

4. Jun Fang, Ji Jie, Yuan Hong-Yong, Zhang Yong-Ming. "Early fire smoke movements and detection in high large volume spaces", Building and Environment, 41, 2006, pp.1482-1493

5. Jinsong Hua, Jian Wang, Kurichi Kumar. "Development of a hybrid field and zone model for fire smoke propagation simulation in buildings", Fire Safety Journal, 40, 2005, pp.199-219

6. Zhuman Fu, George Hadjisophocleous. "A two-zone fire growth and smoke movement model for multi-compartment buildings", Fire Safety Journal, 34, 2000, pp.257-285

7. J.S. Rho, H.S. Ryou. "A numerical study of atrium fires using deterministic models", Fire Safety Journal, 33, 1999, pp.213-29

8. Chen Xiaojun, Yang Lizhong, Deng Zhihua, Fan Weicheng. "A multi-layer zone model for predicting fire behavior in a fire room", Fire Safety Journal. 40, 2005, pp.267-281

9. Richard S. Miller, Don Beasley. "On stairwell and elevator shaft pressurization for smoke control in tall buildings". Building and Environment. 44, 2009, pp.1306-1317

10. Richard S. Miller. "Elevator shaft pressurization for smoke control in tall buildings: The Seattle approach", Building and Environment. 46, 2011, pp.2247-2254

11. Wang Y.L., Gao F.S. "Tests of stairwell pressurization systems for smoke control in a high-rise building", ASHRAE Trans, 110, 2004, pp.185-193

12. Xu X.Y., Li Y.Z., Mao S.H. "Model for neutral-plane location in shaft in fire", Journal of Combustion Science and Technology. 17 2011, pp.375-381

13. Xu X.Y., Li Y.Z., Mao S.H. "A multi-zone model for the neutralplane location in a shaft in fire", Fire Safety Science. 19, 2010, pp.224-231

14. G.P. Mercier, Y. Jaluria. "Fire-induced-flow of smoke and hot gases in open vertical enclosures", Experimental Thermal and Fluid Science. 19, 1999, pp.77-84

15. W.Z. Black. "COSMO-Software for designing smoke control systems in high-rise buildings", Fire Safety Journal, 45, 2010 pp. $337-348$
16. W.Z. Black. "Smoke movement in elevator shafts during a high-rise structural fire". Fire Safety Journal, 44, 2009, pp.168-182

17. W.Z. Black. "Floor pressurization as a means of controlling smoke during a high-rise fire", Engineered Systems January, 2009, pp.46-

18. W.Z. Black. "Use of air handling equipment to manage smoke movement during a high-rise fire", ASHRAE Transactions, 115(1), 2009, pp. $165-81$

19. W. Z. Black. "Computer modeling of stairwell pressurization to control smoke movement during a high-rise fire", ASHRAE Transactions, 117(1), 2011, pp. 15-25

20. W.Z. Black. "Pressurization of floors to improve life safety during a high-rise fire", ASHRAE Transactions, 115 (2), 2009, pp. 278289

21. Qiu Xudong, Gao Fusheng, Wang Yangling. "Review and evaluation on numerical simulation method of smoke movement under building fire", Journal of Natural Disasters. 14(1), 2005, pp.132-138

22. Chen Y.P., Chen L., Zhang M.J. "The analysis and estimation of the plume models in the development of fires", Fire Safety Science. 11(3), 2002, pp.132-136

23. Chen C.K., Yao B. "Applicability of the plume modes for the zone modeling of the smoke in compartment fires", Journal of Combustion Science and Technology. 14(4), 2008, pp.295-299

24. Andrey E. Kovtanyuk, Nikolai D. Botkin, Karl-Henz Hoffmann "Numerical simulations of a coupled radiative-conductive heat transfer model using a modified Monte Carlo method". International Journal of Heat and Mass Transfer, 55(4), 2012, pp.649-654

25. Yong Zhang, Hong-Liang Yi, He-Ping Tan. "Natural element method for radiative heat transfer in two-dimensional semitransparent medium". International Jouranl of Heat and Mass Transfer, 56(1), 2013, 411-423

26. National Fire Protection Association, NFPA 101, Life Safety Code, Section 54.9.2.1, Quincy, MA, 2006

27. Wu, Yeqiu; Li, Angui; Ma, Jiangyan, etc. "Numerical studies on smoke natural filling in an underground passage with validation by reduced-scale experiments", Nature Environment and Pollution Technology, 12 (1), 2013, pp. 35-42

28. Wang Da-Jinn, Chen Thou-Ho, Yin Yen-Hui, "Smoke detection for early fire-alarming system based on video processing", Journal of Digital Information Management, 6(2), 2008, pp.196-202

29. Bakhti, F.Z. "Numerical simulation of mixed convection in a inclined thick duct", Journal of Engineering Science and Technology Review, 4(2), 2011, pp. 152-159 